www.nature.com/bmt

\title{
Erratum
}

\section{Partially mismatched related donor bone marrow transplantation as salvage for patients with AML who failed autologous stem cell transplant}

Godder et al

Correction to: Bone Marrow Transplantation (2001) 28, 1031-1036. DOI: 10.1038/sj/bmt/1703279

Since the publication of the above paper, an error has been identified in the spelling of one of the authors' names. J Mehta appeared as 'J Metha'. Therefore, the authors' names should appear as follows:

KT Godder, J Mehta, KY Chiang, S Adams, F van Rhee, S Singhal, K Higgins-Smith, W O'Neal, S DeRienzo and JP Henslee-Downey

Bone Marrow Transplantation (2002) 29, 1007. DOI: $10.1038 / \mathrm{sj} / \mathrm{bmt} / 1703634$ 